\title{
Strength and Cost Analysis of New Steel Sets as Roadway Support Project in Coal Mines
}

\author{
Qinghai Li $\left(\mathbb{D},{ }^{1}\right.$ Renshu Yang, ${ }^{2}$ Jingkai Li $\mathbb{D},{ }^{1}$ He Wang, ${ }^{1}$ and Zhijie Wen ${ }^{1}{ }^{1}$ \\ ${ }^{1}$ State Key Laboratory of Mining Disaster Prevention and Control Co-Founded by Shandong Province and \\ the Ministry of Science and Technology, Shandong University of Science and Technology, Qingdao 266590, China \\ ${ }^{2}$ School of Mechanics and Civil Engineering, China University of Mining and Technology (Beijing), Beijing 100083, China
}

Correspondence should be addressed to Zhijie Wen; sdust0532@gmail.com

Received 2 May 2018; Accepted 17 September 2018; Published 18 October 2018

Academic Editor: Guillaume Bernard-Granger

Copyright (C) 2018 Qinghai Li et al. This is an open access article distributed under the Creative Commons Attribution License, which permits unrestricted use, distribution, and reproduction in any medium, provided the original work is properly cited.

Roadway support in swelling soft rocks in coal mines has become a critical challenge in recent years. For deformation control in swelling soft rocks, high strength sets are preferred in sites. But high strength always means high costs. Therefore, higher strength sets with not too much cost will be more welcomed in situ. Based on this, three new sets, including a floor beam set, a roof + floor beams set, and a roof + floor beams + braces set, have been developed in the present research. Strength comparisons and costs comparisons have been conducted in this research. Results illustrate that compared with the original set, in the floor beam set, the relative strength of bottom corners reaches 2.964, while the relative cost reaches 1.294; compared with the original set, in the roof + floor beams set, the relative strength of the top arch reaches 2.345 , while the relative strength of bottom corners reaches 2.964, and the relative cost reaches 1.568; and compared with the original set, in the roof + floor beams + braces set, the relative strength of the top arch reaches 2.635 , and the relative strength of bottom corners reaches 5.905, but the relative cost reaches 1.930. Floor beam set and roof + floor beams set illustrate higher strength and not too higher costs than the original set. Although the roof + floor beams + braces set exhibit much higher strength, they also demonstrate much higher costs than the original set. These new sets can be chosen according to different geological conditions in situ.

\section{Introduction}

There is high demand for roadway support in swelling soft rocks in recent years [1-6]. Swelling soft rocks always contain clay minerals (smectite, kaolinite, etc.) and become highly deformable $[7,8]$ when interacted with water and air. As examples shown in previous studies $[9,10]$, the roadway deformed largely and continuously in this rock, leading to a very dangerous situation for people working in these sites. In swelling soft rocks, support systems must have sufficient bearing capacity and strength [11].

For roadway control, bolting, cabling, and steel sets supporting [12-18] are commonly used in situ. Based on bolting and cabling, a variety of new support approaches have been developed for complicated geological conditions, such as bolting with large deformation while keeping constant resistance $[19,20]$, high prestress, high-strength support system [21], high-strength cable support system [22], grouted bolting system $[23,24]$, etc. Steel sets are another effective tool for roadway support in many cases [25-27]. There are many kinds of steel sets used in situ. Sets made of U-section steels and I-section steels are two kinds of sets widely used in situ. For U-section steel sets, types of 29, 36 , and $40 \mathrm{U}$-section steels are commonly used in situ, while for I-section steel sets, types of 9, 11, and 12 mines used I-section steels are commonly used in situ. Due to high demand for roadway support in swelling soft rocks, it is realized that the high strength set is an effective alternative for roadway control in these rocks [28]. However, U-section steel sets and I-section steel sets all failed in swelling soft rocks, such as in ventilation crosscut in No. 1 Mine of Chagannuoer (short as NMC) in China [10]. In view of this, new sets with higher strength need to be developed for roadway support in swelling soft rocks. 
In NMC, the ventilation crosscut was in shape of the semiarch with the dimension of $4300 \mathrm{~mm}$ in height and $5000 \mathrm{~mm}$ in width, and accordingly, the supporting set, with $1000 \mathrm{~mm}$ inverse arch in the floor, was shown in (Figure 1(a)). This type of set, commonly used in situ, is designated as the original set for subsequent analysis. Based on the original set, three new sets, including a floor beam set, a roof + floor beams (RFB) set, and a roof + floor beams + braces (RFBB) set have been developed [29]. In the floor beam set, a floor beam is added in the bottom corner compared with the original set (Figure 1(b)). In the RFB set, one more roof beam, which is $2700 \mathrm{~mm}$ above the floor beam, is added in the top arch than the floor beam set (Figure 1(c)). In the RFBB set, four more braces with $45^{\circ}$ angle to the roof or floor beam are added in top and bottom arches than the RFB set (Figure 1(d)). These three new sets have not been used in situ. To test strengths of new sets, four scaled sets of three new sets and one original set are produced and tested in loading experiments. Strength comparisons between new sets and original sets are conducted based on stress analysis. It is well known that higher strength sets always means higher costs. For example, 36 U-section steel (short as U36) sets demonstrate higher strength than 29 U-section steel (short as U29) sets, and the costs of U36 sets are also higher than U29 sets. For cost-performance analysis, the new set with much higher strength and less cost will be desirable. Therefore, besides strength comparisons, costs comparisons are also conducted in this study. It is assumed that all sets are manufactured by the same steel, and therefore, cost comparisons can be represented by total mass comparisons in different sets. In situ, the set was decomposed into several segments on ground and assembled in underground driving face. The total mass of every set can be derived by total length of all segments and steel's unit mass. Based on the same steel's unit mass, cost comparisons can be obtained combined with sets dimensions. Based on strength and costs analysis, cost-effective sets can be chosen according to roadway deformations caused by different effects.

In the present study, new steel sets for roadway support in swelling soft rocks are developed in Section 1. Loading experiments for strength comparisons are introduced in Section 2. The experiment is verified by structural mechanics analysis in Section 3. Strength comparisons and cost comparisons between different sets and discussions are conducted in Section 4. Finally, conclusions are shown in Section 5.

\section{Experimental Design}

2.1. Scaled Sets in Experiments. In order to test the strength of different new sets, loading experiments are designed in this section. Because of the small loading frame in the laboratory, experimental sets were scaled to 0.4 times of full-scale sets (i.e., the size ratio between scaled sets and full-scale sets is 0.4). The nearly material 12.6 ordinary I-section steel (I12.6) (parameters are shown in Table 1) [29], with ratios of 0.40, 0.53, and 0.55 to U36 in parameters of the sectional area, moment of inertia, and section modulus, was chosen as the scaled sets material. After manufacturing, the scaled original set was decomposed into four segments: top arch, bottom arch, and two branches on the ground. Two plates with the bolt holes

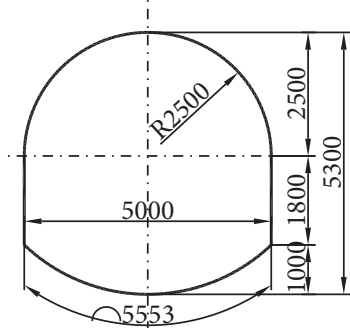

(a)

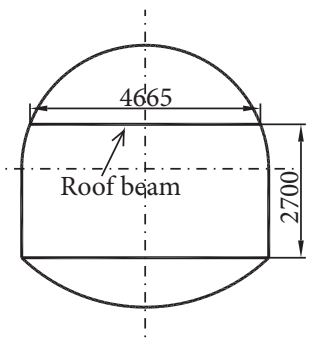

(c)

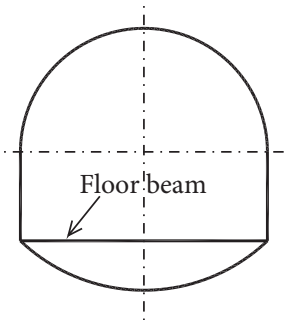

(b)

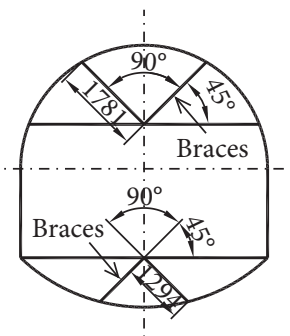

(d)
FIgURE 1: Sets' patterns and dimensions (units: $\mathrm{mm}$ ): (a) original set (universally used in situ); (b) floor beam set; (c) RFB set; (d) RFBB set [29].

were welded at two ends of each segment. Four segments were connected by the bolts in underground working space. Based on the original set, other beams or braces, also made of I12.6, were welded progressively on new sets.

2.2. Loading System. From site observations, it was found that roof subsidence and sides squeezing inward occurred almost all the time [9]. Therefore, in the tests, ignoring minor loads, concentrated loads $F_{1}$ and $F_{2}$ were assumed as the main forces applied on the set's top arch, bottom arch, and two bottom corners (Figure 2). According to ground stress measurements in situ [9], the ratio of maximum horizontal principal stress to vertical stress was 1.77 . For convenient loading, the ratio of $F_{2}$ to $F_{1}$ was chosen as 2.0 in the experiments. During loading, $F_{1}$ was loaded by a horizontal hydraulic cylinder and $F_{2}$ was loaded by a vertical hydraulic cylinder (Figure 3). In loading, the force control method is used firstly, and force of $F_{2}$ keeps 2 times of $F_{1}$ in this stage. While the top arch or bottom corners approximately yield, the force control method is replaced by the displacement control method, and loading displacement of $F_{2}$ keeps 2 times of loading displacement $F_{1}$.

2.3. Stress Monitoring. For set in situ, the top arch mainly bended inward, while the bottom corners mainly squeezed inward. According to the mechanics of the material [30], the maximum bending stress mainly occurs at set's inside flange of the top arch, while the maximum shearing stress mainly occurs at the middle of the set's web at the two bottom corners. Therefore, \#1 gauge is pasted at the middle of the top arch's inside flange and used for bending strain monitoring, while \#2 strain gauge is pasted at the middle of the bottom corner's web and used for shearing strain monitoring (Figure 4). BX120-3AA strain gauges, with 
TABle 1: Parameters of U36 and I12.6 [29].

\begin{tabular}{lcccccc}
\hline Pattern & $\begin{array}{c}\text { Unit mass, } \\
m(\mathrm{~kg} / \mathrm{m})\end{array}$ & $\begin{array}{c}\text { Sectional area, } \\
A\left(\mathrm{~cm}^{2}\right)\end{array}$ & $\begin{array}{c}\text { Section thickness at } \\
\text { neutral axis, } d(\mathrm{~cm})\end{array}$ & $\begin{array}{c}\text { Moment of inertia, } \\
I\left(\mathrm{~cm}^{4}\right)\end{array}$ & $\begin{array}{c}\text { Elastic modulus, } \\
E(\mathrm{GPa})\end{array}$ & $\begin{array}{c}\text { Section modulus, } \\
W\left(\mathrm{~cm}^{3}\right)\end{array}$ \\
\hline $\mathrm{U} 36$ & 35.87 & 45.69 & 1.56 & 928.65 & 200 & 141.22 \\
$\mathrm{I} 12.6$ & 14.223 & 18.118 & 0.5 & 488 & 200 & 77.5 \\
\hline
\end{tabular}

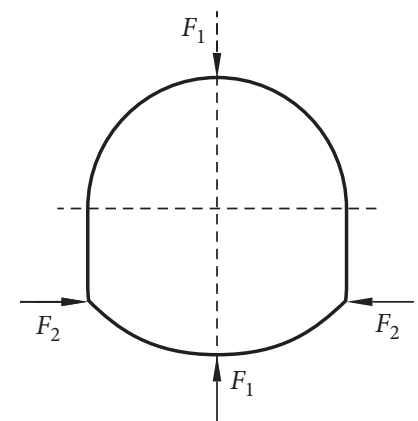

FIgURE 2: Loading state on the set.

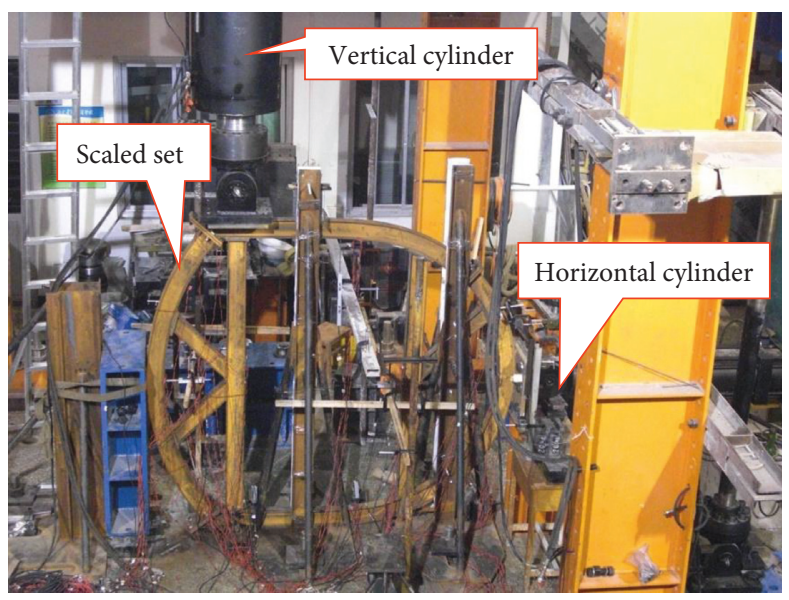

FIGURE 3: Loading system in the laboratory.

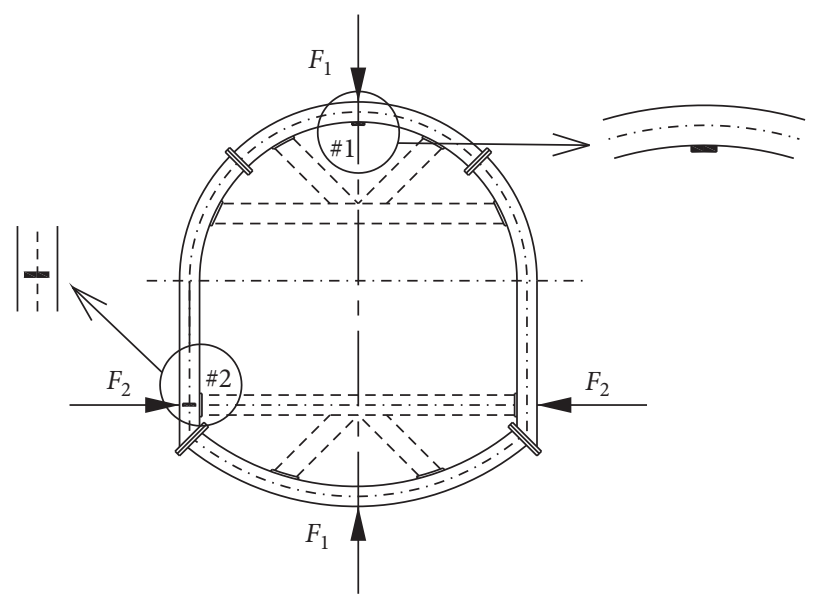

Figure 4: Strain gauges on the scaled set. 
a sensitive grid of $2 \mathrm{~mm}$ in width and $3 \mathrm{~mm}$ in length and with a measurement range from -6000 to $6000 \mu \varepsilon$, are used in the tests. After strains are measured, stress can be derived by strain multiplied with material's elasticity modulus E.

\section{Experimental Verification}

In Figure 5(a), the set is in the static equilibrium state. Hence, the set can be equivalent to the structure with one hinge on the bottom arch (Figure 5(b)). Moreover, due to the set's geometry characteristics (i.e., the set can be considered as a secondary statically indeterminate symmetric structure), the structure in Figure 5(b) can be represented by the half plotted in Figure 5(c). Then, at point $\mathrm{D}$, three hinges are equivalent to a fixed constraint, and at point $\mathrm{A}$, two constraints can be replaced by unknown moment $X_{1}$ and force $X_{2}$; correspondingly, the final stress state in the half set is shown in Figure 5(d). When $X_{1}$ and $X_{2}$ are determined, force and moment in any locations can be derived. Ignoring the steel's section area and self-weight, equilibrium formulas by the force method [31] are as follows:

$$
\left\{\begin{array}{l}
\delta_{11} X_{1}+\delta_{12} X_{2}+\Delta_{1 p}=0 \\
\delta_{21} X_{1}+\delta_{22} X_{2}+\Delta_{2 p}=0
\end{array}\right.
$$

where $\Delta_{1 p}$ and $\Delta_{2 p}$ are displacements induced by $F_{1}$ and $F_{2}$, $\delta_{11}$ and $\delta_{21}$ are displacements induced by $X_{1}=1$, and $\delta_{12}$ and $\delta_{22}$ are displacements induced by $X_{2}=1$. And,

$$
\begin{aligned}
\delta_{11} & =\sum \int \frac{\bar{M}_{1}^{2}}{E I} d s=\int_{\mathrm{AB}} \frac{{\overline{M_{1}}}^{2}}{E I} d s+\int_{\mathrm{BC}} \frac{{\overline{M_{1}}}^{2}}{E I} d s+\int_{\mathrm{CD}} \frac{{\overline{M_{1}}}^{2}}{E I} d s, \\
\delta_{22} & =\sum \int \frac{\bar{M}_{2}^{2}}{E I} d s=\int_{\mathrm{AB}} \frac{{\overline{M_{2}}}^{2}}{E I} d s+\int_{\mathrm{BC}} \frac{{\overline{M_{2}}}^{2}}{E I} d s+\int_{\mathrm{CD}} \frac{{\overline{M_{2}}}^{2}}{E I} d s, \\
\delta_{12} & =\delta_{21}=\sum \int \frac{\overline{M_{1} M_{2}}}{E I} d s \\
& =\int_{\mathrm{AB}} \frac{\overline{M_{1} M_{2}}}{E I} d s+\int_{\mathrm{BC}} \frac{\overline{M_{1} M_{2}}}{E I} d s+\int_{\mathrm{CD}} \frac{\overline{M_{1} M_{2}}}{E I} d s, \\
\Delta_{1 p} & =-\sum \int \frac{\overline{M_{1}} M_{p}}{E I} d s \\
& =-\left(\int_{\mathrm{AB}} \frac{\overline{M_{1}} M_{p}}{E I} d s+\int_{\mathrm{BC}} \frac{\overline{M_{1}} M_{p}}{E I} d s+\int_{\mathrm{CD}} \frac{\overline{M_{1}} M_{p}}{E I} d s\right), \\
\Delta_{2 p} & =-\sum \int \frac{\overline{M_{2}} M_{p}}{E I} d s \\
& =-\left(\int_{\mathrm{AB}} \frac{\overline{M_{2}} M_{p}}{E I} d s+\int_{\mathrm{BC}} \frac{\overline{M_{2}} M_{p}}{E I} d s+\int_{\mathrm{CD}} \frac{\overline{M_{2}} M_{p}}{E I} d s\right),
\end{aligned}
$$

where $\overline{M_{1}}$ and $\overline{M_{2}}$ are the moments when $X_{1}=1$ and $X_{2}=$ 1 are applied on the structure, respectively; $M_{p}$ is the

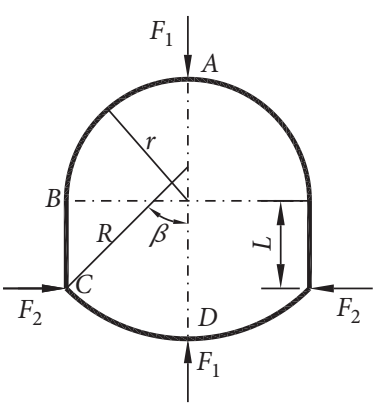

(a)

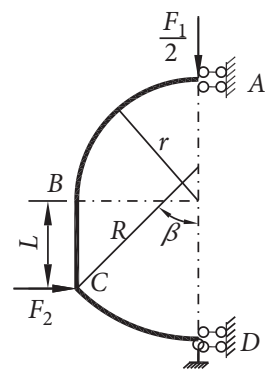

(c)

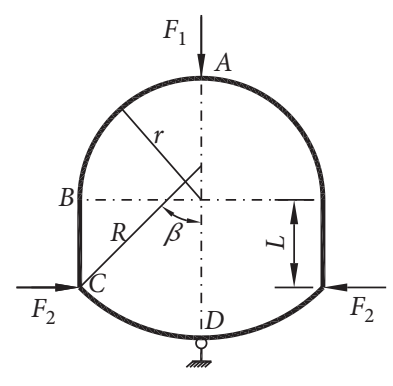

(b)

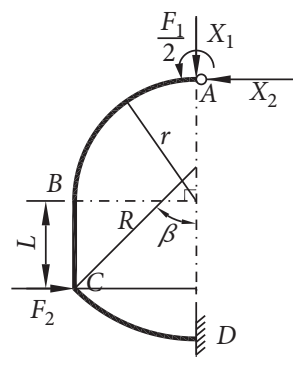

(d)
FIgURE 5: Structural mechanics analysis on the set: (a) set in the static equilibrium state; (b) set with one hinge on the bottom arch; (c) stress state of the half set; (d) final stress state of the half set.

moment when $F_{1}$ and $F_{2}$ are applied on the structure simultaneously; $E$ is the steel's elasticity modulus; $I$ is the moment of inertia; and $s$ is the structure's axial length of different segments.

The moment $M$ is assumed as positive when the set's inner side is in tension. The parameters can be obtained by integral as

$$
\begin{aligned}
\delta_{11}= & \frac{1}{E I}\left(\frac{\pi r}{2}+L+R \beta\right), \\
\delta_{22}= & \frac{1}{E I}\left[r^{3}\left(\frac{3 \pi}{4}-2\right)+r^{2} L+r L^{2}+\frac{L^{3}}{3}\right. \\
& +R \beta(r+L-R \cos \beta)^{2}+\frac{R^{3}(\sin 2 \beta+2 \beta)}{4} \\
& \left.+2 R^{2}(r+L-R \cos \beta) \sin \beta\right],
\end{aligned}
$$

$$
\begin{aligned}
\delta_{12}= & \delta_{21}=\frac{1}{E I}\left[r^{2}\left(\frac{\pi}{2}-1\right)+r L+\frac{L^{2}}{2}+R \beta(r+L-R \cos \beta)\right. \\
& \left.+R^{2} \sin \beta\right],
\end{aligned}
$$

$$
\begin{aligned}
\Delta_{1 p}= & -\frac{1}{E I}\left[\frac{F_{1}\left(r^{2}+r L+R^{2}-R^{2} \cos \beta\right)}{2}\right. \\
& \left.+F_{2} R^{2}(\sin \beta-\beta \cos \beta)\right],
\end{aligned}
$$




$$
\begin{aligned}
\Delta_{2 p}= & -\frac{1}{E I}\left[\frac{F_{1}\left(r^{3}+2 r^{2} L+r L^{2}\right)}{4}+(r+L-R \cos \beta)\right. \\
& \cdot\left(\frac{F_{1} R^{2}(1-\cos \beta)}{2}+F_{2} R^{2}(\sin \beta-\beta \cos \beta)\right) \\
& \left.+\frac{F_{1} R^{3}(1-\cos 2 \beta)}{8}+\frac{F_{2} R^{3}(2 \beta-\sin 2 \beta)}{4}\right],
\end{aligned}
$$

where $r$ and $R$ refer to the radius of the top arch and bottom arch, $\beta$ is the central angle of the half bottom $\operatorname{arch}$, and $L$ is the height of the set's straight wall.

At point $\mathrm{A}$, according to static equilibrium conditions, we can get that

$$
\sigma_{\mathrm{A}}=\frac{X_{1}}{W}-\frac{X_{2}}{A}
$$

As well as at point $C$, shear stress $F_{C}$ is equivalent to $F_{2}-X_{2}$. So $\tau_{\mathrm{C}}$ can be derived as

$$
\tau_{\mathrm{C}}=\frac{F_{\mathrm{C}} S}{I d}=\frac{\left(F_{2}-X_{2}\right) S}{I d},
$$

where $S$ is the static moment for section to neutral axis and $d$ is the section thickness at neutral axis.

The parameters of the full-scale set are $\pi=3.14, L=$ $1.8 \mathrm{~m}, r=2.5 \mathrm{~m}, R=3.535 \mathrm{~m}$, and $\beta=\pi / 4$. According to size ratio 0.4 , the parameters of the scaled set can be determined as $\pi=3.14, L^{\prime}=0.72 \mathrm{~m}, r^{\prime}=1 \mathrm{~m}, R^{\prime}=1.414 \mathrm{~m}$, and $\beta^{\prime}=\pi / 4$.

According to Equations (3) (7), the following values can be calculated as

$$
\begin{aligned}
& \delta_{11}=3.4031 \frac{1}{E I}, \\
& \delta_{22}=6.1482 \frac{1}{E I}, \\
& \delta_{12}=\delta_{21}=3.7635 \frac{1}{E I}, \\
& \Delta_{1 p}=-\frac{1.1528 F_{1}+0.3034 F_{2}}{E I}, \\
& \Delta_{2 p}=-\frac{1.3039 F_{1}+0.6219 F_{2}}{E I} .
\end{aligned}
$$

From formula (1), $X_{1}$ and $X_{2}$ can be expressed as

$$
\begin{aligned}
& X_{1}=0.3231 F_{1}-0.0704 F_{2}, \\
& X_{2}=0.0143 F_{1}+0.1443 F_{2} .
\end{aligned}
$$

When $F_{2}=2 F_{1}$, by formulas (8) and (9), $\sigma_{\mathrm{A}}$ and $\tau_{\mathrm{C}}$ can be expressed as

$$
\sigma_{\mathrm{A}}=\frac{X_{1}}{W}-\frac{X_{2}}{A}=\frac{0.1823 F_{1}}{W}-\frac{0.3029 F_{1}}{A}
$$

where $W$ is the section modulus and $A$ is the sectional area.

$$
\tau_{C}=\frac{\left(F_{2}-X_{2}\right) S}{I d}=\frac{0.8486 F_{2} S}{I d} .
$$

For $I 12.6, A=18.118 \mathrm{~cm}^{2}, I=488 \mathrm{~cm}^{4}, S=44.985 \mathrm{~cm}^{3}$, $d=5 \mathrm{~mm}$, and $W=77.5 \mathrm{~cm}^{3}$, from formulas (12) and (13), it can be obtained that

$$
\begin{aligned}
\sigma_{A I 12.6} & =2.185 \times 10^{-3} F_{1} \mathrm{MPa}, \\
\tau_{C I 12.6} & =1.564 \times 10^{-3} F_{2} \mathrm{MPa} .
\end{aligned}
$$

For the scaled original set, the experimental stresses $\sigma_{A I 12.6}$ and $\tau_{C I 12.6}$ can be derived by strains of gauges $\# 1$ and $\# 2$ monitored in the test. When $F_{2}=2 F_{1}$ (i.e., consistent with experimental loading), $\sigma_{A I 12.6}$ of calculated and experimental results are shown in Figure $6(\mathrm{a})$, and $\tau_{C I 12.6}$ are shown in Figure 6(b) (compressive stress is defined as negative). It can be observed that the experimental results are in good agreement with the calculated results. Therefore, the experimental methodology is valid.

\section{Experimental Results and Discussion}

For comparison, the scaled original set, scaled floor beam set, scaled RFB set, and scaled RFBB set are defined as set 1 , set 2 , set 3 , and set 4 , respectively. Under same loads and in the same positions, higher strength sets account for lower stresses in loading experiments. Therefore, the relative strength $Q$ is defined as the ratio of stresses in different sets. For example, when stresses in the top arch are $\sigma_{1}$ in set 1 and $\sigma_{2}$ in set 2 , compared to the set 1 , the relative strength of the top arch in the set 2 can be got as $\sigma_{1} / \sigma_{2}$. As shown in following sections, as loads increasing, stresses in experiments increased linearly, so the relative strength $Q$ can be obtained as the ratio between different slopes of monitored stress curves, namely,

$$
Q=\left|\frac{k_{i}}{k_{j}}\right|,
$$

where $k_{i}$ is the slope of the stress curve in the set by comparison and $k_{j}$ is the slope of the stress curve in another set.

\subsection{Strength Comparisons}

4.1.1. Stress in the Top Arch. Linear relationship between horizontal loads $F_{1}$ and top arch bending stresses $\sigma_{\mathrm{A}}$, which are derived from \# 1 strains in the tests, is shown in Figure 7. $\left|k_{1}\right|,\left|k_{2}\right|,\left|k_{3}\right|$, and $\left|k_{4}\right|$, corresponded to curve slopes in sets $1,2,3$, and 4 are $2.143,2.143,0.914$, and 0.833 , respectively.

Due to difference in curve slopes, the stresses can be divided into two types: stresses in sets 1 and 2 and stresses in sets 3 and 4 . For the first type (stresses in sets 1 and 2), the curve slopes $\left|k_{1}\right|$ and $\left|k_{2}\right|$ are approximately the same and equal to 2.143. In sets 1 and 2, there is no roof beam in the top arch, but a floor beam in set 2 . In spite of this, the top arch presents approximately the same strength. Therefore, it can be decided that the floor beam plays no effect in the top arch reinforcing, and the top arch without the roof beam corresponds to the same strength. For the second type, 


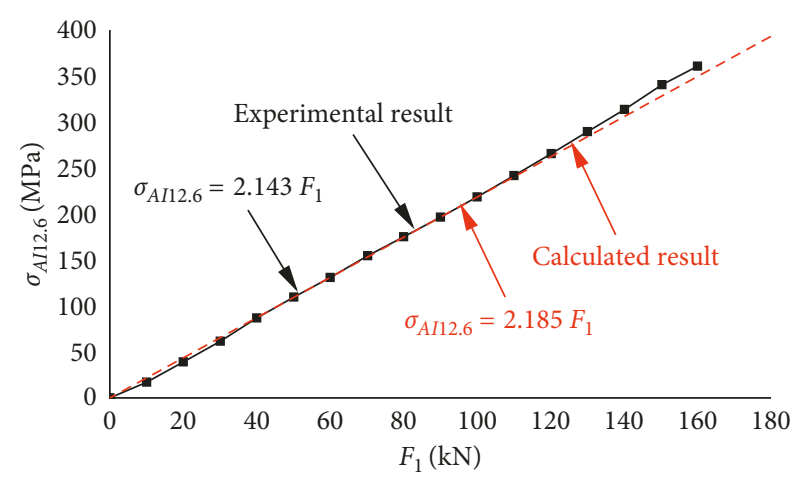

(a)

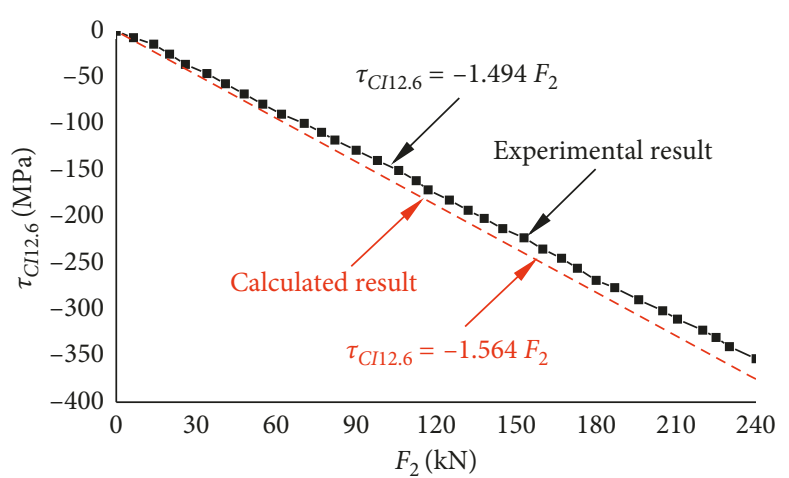

(b)

Figure 6: Results comparisons: (a) calculated results and experimental results of $\sigma_{A I 12.6}$; (b) calculated results and experimental results of $\tau_{C I 12.6}$.

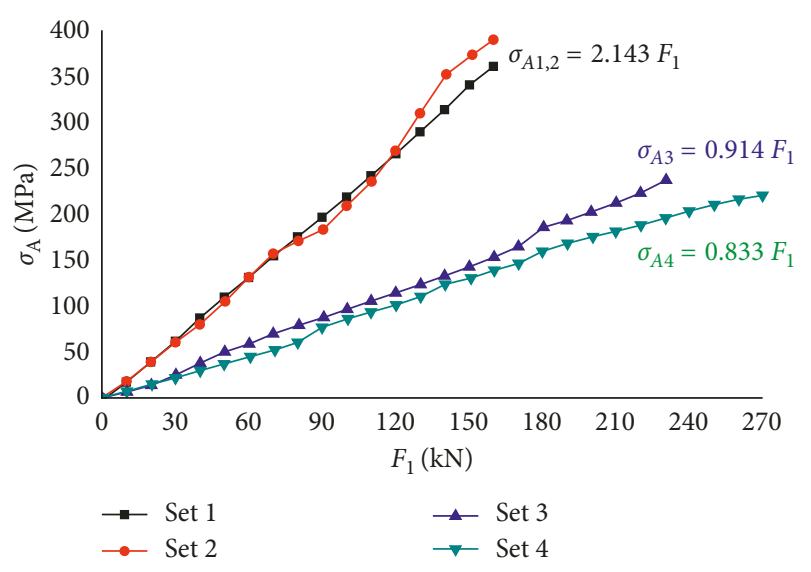

Figure 7: Bending stresses in the top arch.

stresses in sets 3 and 4 , the curve slopes $\left|k_{3}\right|$ and $\left|k_{4}\right|$ are equal to 0.914 and 0.833 , respectively. Compared with set 3 , in set 4 , there are two more braces in the bottom arch and two more braces in the top arch, and the relative strength of the top arch reaches $1.097\left(\left|k_{3} / k_{4}\right|\right)$ in set 4 . While there is greater distance from bottom arch braces to top arch than distance from the floor beam to the top arch, considering the floor beam plays no effect in top arch reinforcing, it is determined that bottom arch braces also play no effect in top arch reinforcing. Therefore, from set 3 to set 4 , the little reinforcing effect is mainly induced by two top arch braces.

Compared with set 1 , in set 3 , the relative strength of the top arch reaches $2.345\left(\left|k_{1} / k_{3}\right|\right)$. Thus, the roof beam plays an obviously effect in top arch reinforcing. This is because when load applied on set with the roof beam, the roof beam will provide a pulling or supporting stresses to constrain the outward or inward movement of the top arch. Hence, the top arch with the roof beam can be considered as a triangle structure (Figure 8), which can provide higher strength than the top arch without the roof beam.

4.1.2. Stress in the Bottom Corner. Linear relationship between vertical loads $F_{2}$ and bottom corners shearing stress $\tau_{\mathrm{C}}$, which are derived from $\# 2$ strains in the tests, is shown in

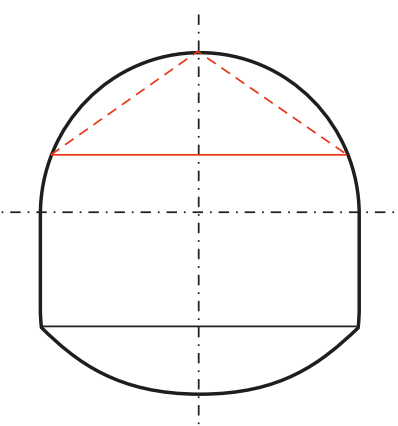

FIgURE 8: Similar triangle structure in the top arch.

Figure 9. The curve slopes in sets $1,2,3$, and 4 (i.e., $\left|k_{1}\right|,\left|k_{2}\right|$, $\left|k_{3}\right|$, and $\left.\left|k_{4}\right|\right)$ are $1.494,0.515,0.492$, and 0.253 , respectively. For sets 2 and 3, the slopes are close to each other, which indicate that the bottom corners present approximately the same strength regardless of one more roof beam in set 3 . Therefore, it can be decided that the roof beam plays little effect on the bottom corners reinforcing. Therefore, in sets 2 and 3 , the $F_{2}-\tau_{\mathrm{C}}$ relationships can be considered as the same and the associated slope $\left|k_{23 \text { ave }}\right|$ can be determined as 0.504 (i.e., the average of $\left|k_{2}\right|$ and $\left|k_{3}\right|$ ).

For a given load, the stress at the bottom corners in set 1 (without a floor beam) is much bigger (i.e., more negative) than those in sets 2, 3, and 4 (with a floor beam). Compared with set 1 , the relative strength of the bottom corners in sets 2 and 3 is $2.964\left(\left|k_{1} / k_{23 a v e}\right|\right)$. Therefore, it can be decided that the floor beam plays a pronounced effect in bottom corners strengthening. When two corners tend to move outward, the floor beam can provide pulling force to restrain the potential movement; meanwhile, when two corners tend to move inward, the floor beam can also provide reaction force to counter the outside load, and thus the floor beam is effective in bottom corners reinforcing.

In set 4 , the bottom corners present a much higher strength than sets 2 and 3 . Compared with set 1 , in set 4 , the relative strength of the bottom corners reaches 5.905 $\left(\left|k_{1} / k_{4}\right|\right)$; meanwhile, compared with set 3 , the relative strength of the bottom corners is $1.992\left(\left|k_{23 \text { ave }} / k_{4}\right|\right)$. There 


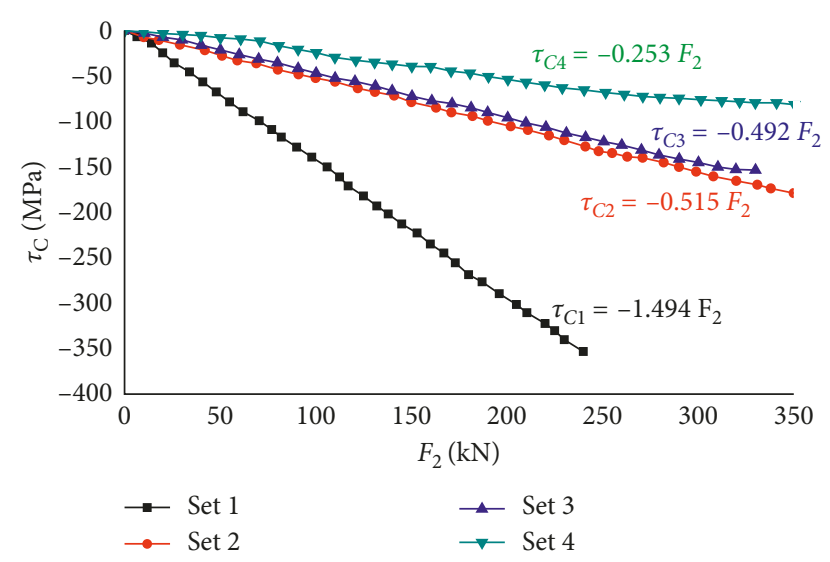

FIGURE 9: Shearing stresses in the bottom corner.

are roof beam and floor beam in set 3 , while there are roof beam, floor beam, and four braces in set 4 . Thus, four braces also play an obvious effect in bottom corners reinforcing. While there is greater distance from top arch braces to bottom corners than distance from roof beam to bottom corners, considering the roof beam even plays little effect on bottom corners reinforcing, and it can be determined that top arch braces also play no effects in bottom corners reinforcing. Hence, the four braces reinforcing effect is mainly generated by two bottom arch braces. When two braces added, the floor beam, two braces, and bottom arch can form two triangles (Figure 10), which can improve the component force along the floor beam, and improve the capacity of the bottom corners. Therefore, both floor beam and two bottom braces exert a pronounced effect in bottom corners reinforcing.

4.2. Cost Comparisons. Through the connection plates, four segments of the top arch, bottom arch, and two branches were connected by bolts in underground. Other beams or braces were welded progressively on the scaled sets. The costs of connection bolts, connection plates, and welding costs are approximately the same and could not be eliminated in each set; therefore, those costs have not been considered in costs comparisons. Besides those costs, the material cost of each set is the principal investment and can be derived by total mass and unit price of steel. As the same unit price of steel, the investment comparison of every set was equivalent to the mass comparison of every set. The total mass of every set can be derived by the length of all segments (Figure 1) and steel's unit mass (Table 1). As the same unit mass of each segment, the relative cost $C$ can be derived as the length ratio of all segments between different sets, namely,

$$
C=\frac{L_{i}}{L_{j}},
$$

where $L_{j}$ is the total length of all segments in set by comparing and $L_{i}$ is the total length of all segments in another set.

As the floor beam plays little effect in top arch strengthening, compared with set 1 , for the roof beam set

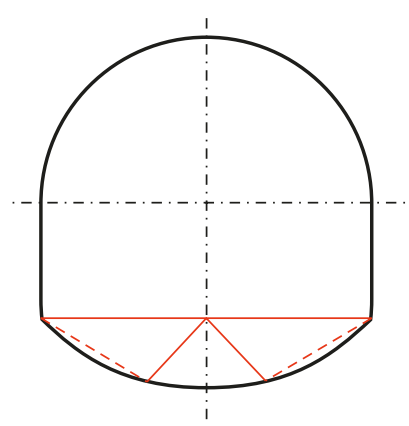

Figure 10: Similar triangle structures in the bottom arch.

(i.e., only the roof beam added in the original set), the top arch's relative strength can be determined as 2.452, as the same relative strength of the top arch in set 3 . Compared with the original set, relative cost and relative strength of the scaled sets are summarized in Table 2.

Compared with the original set, the relative cost of the floor beam set is improved to 1.294 and the relative strength of the bottom corners is enhanced to 2.964. Hence, the floor beam set can be used to control roadway with large deformation around the bottom corners. When roof beam added only, the relative cost of the roof beam set is improved to 1.274 and the relative strength of the top arch reaches 2.345. Therefore, the roof beam set can be used to control roadway with deformation near the top arch. When the roof beam and floor beam added simultaneously, the relative cost of the RFB set increases to 1.568 and the relative strength of the top arch and bottom corners reach 2.345 and 2.964, respectively. Therefore, the RFB set can be used to control large deformation simultaneously near the top arch and bottom corners. When the roof beam, floor beam, and four braces added simultaneously, the relative cost of the RFBB set is improved to 1.930 and the relative strength of the top arch and bottom corners reach 2.635 and 5.905, respectively. The relative strength of the RFBB set is much higher than that of the original set, but the relative cost increases much bigger (about 2 times) as well. Thus, this new set is not recommended for in situ application. As stated above, the floor beam, roof beam, and two bottom braces all play pronounced effect on new sets reinforcing, and in this research, sets with fixed positions beams and braces have been tested in experiments. Whether sets with beams and braces in other positions illustrate higher strength or not needs is to be researched in the future. In this research, the beams and braces in sets are made of the same material as the frame. Whether sets reinforced by beams and braces with less unit mass illustrate higher cost-performance or not needs is to be researched in the future.

The installation of sets is completed in roadway driving face after each segment produced on the ground. However, the underground working space is relatively limited. Thus, if each segment is heavily, the assembling operation will become extremely difficult in underground space. Therefore, the mass of each segment and its resultant strength must be fully considered during the roadway support design. As stated above, total mass of each new set is heavier than the original 
TABLE 2: Strength and cost comparisons between original set and new sets.

\begin{tabular}{lccc}
\hline Pattern & $\begin{array}{c}\text { The relative } \\
+ \text { cost/mass }\end{array}$ & $\begin{array}{c}\text { The relative } \\
\text { strength of the } \\
\text { top arch }\end{array}$ & $\begin{array}{c}\text { The relative } \\
\text { strength of the } \\
\text { bottom corners }\end{array}$ \\
\hline Original set & 1.0 & 1.0 & 1.0 \\
Floor beam set & 1.294 & 1.0 & 2.964 \\
Roof beam set & 1.274 & 2.345 & 1.0 \\
RFB set & 1.568 & 2.345 & 2.964 \\
RFBB set & 1.930 & 2.635 & 5.905 \\
\hline
\end{tabular}

set, but the mass of each segment in every new set is not heavier than the original set (all sets are assumed to be composed by the top arch, bottom arch, two branches, as well as internal beams and braces). Therefore, the associated installation of new sets is no more difficult than the original set.

\section{Conclusion}

To control large deformations in swelling soft rocks, based on the original set, a series of new sets, which include a floor beam set, a RFB set, and a RFBB set, are proposed. To evaluate the performance of new sets, four scaled sets have been produced and tested by loading experiments. Results indicate that compared with the original set, in the floor beam set, the relative strength of the bottom corners reaches 2.964, while the relative cost reaches 1.294; compared with the original set, in the RFB set, the relative strength of the top arch reaches 2.345 , while the relative strength of the bottom corners reaches 2.964, and the relative cost reaches 1.568; and compared with the original set, in the RFBB set, the relative strength of the top arch reaches 2.635, and the relative strength of the bottom corners reaches 5.905, but the relative cost reaches 1.930. These new sets all present higher strength than the original set and will provide new support approaches for large deformation roadways caused by different effects.

\section{Data Availability}

The data used to support the findings of this study are available from the corresponding author upon request.

\section{Conflicts of Interest}

The authors declare that there are no conflicts of interest regarding the publishing of this paper.

\section{Acknowledgments}

This study was supported by the National Natural Science Foundation of China (grant no. 51604164), Program of National Key Research and Development (grant no. 2016YFC0600903), Program of Introducing Talents of Underground Clean Energy Development (grant no. B14006), Program of the Natural Science Foundation of Shandong Province (grant no. ZR2018 MEE001), and by the Program of Youth Teacher Growth Plan in Shandong Province.

\section{References}

[1] M. Bilir, "Swelling problems and triaxial swelling behavior of claystone: a case study in Tire, Turkey," Scientific Research and Essays., vol. 6, no. 5, pp. 1106-1116, 2011.

[2] V. Y. Chertkov and I. Ravina, "Networks originating from the multiple cracking of different scales in rocks and swelling soils," International Journal of Fracture, vol. 128, no. 1, pp. 263-270, 2004.

[3] V. Ghiasi, S. Ghiasi, and A. Prasad, "Evaluation of tunnels under squeezing rock condition," Journal of Engineering, Design and Technology, vol. 10, no. 1, pp. 168-179, 2012.

[4] B. Schädlich, T. Marcher, and H. F. Schweiger, "Application of a constitutive model for swelling rock to tunnelling," Geotechnical Engineering, vol. 44, pp. 47-54, 2013.

[5] K. Serafeimidis and G. Anagnostou, "On the timedevelopment of sulphate hydration in anhydritic swelling rocks," Rock Mechanics and Rock Engineering, vol. 46, no. 3, pp. 619-634, 2013.

[6] M. Thomas, K. Utz, R. V. Maximiliano, and T. Theodoros, "Influence of hematite coating on the activation of the swelling potential of smectite-bearing rocks," Rock Mechanics and Rock Engineering, vol. 46, no. 4, pp. 835-847, 2013.

[7] B. Christoph, H. Peter, and Z. Eric, "Impact of tunneling on regional groundwater flow and implications for swelling of clay-sulfate rocks," Engineering Geology, vol. 117, no. 3-4, pp. 198-206, 2011.

[8] S. Walter, K. K. Peter, and S. Georg, "Role of brittle fracture on swelling behaviour of weak rock tunnels: hypothesis and qualitative evidence Sprödbruch in wenig festem Fels als Auslöser von Quellvorgängen: Beobachtungen und Analysen," Geomechanics and Tunnelling, vol. 3, no. 5, pp. 583-596, 2010.

[9] Q. H. Li, W. P. Shi, and Z. C. Qin, "Effect of bolting on roadway support in extremely weak rock," SpringerPlus, vol. 5, no. 1, pp. 1-18, 2016.

[10] Q. H. Li, W. P. Shi, and R. S. Yang, "Deformation mechanisms in a coal mine roadway in extremely swelling soft rock," SpringerPlus, vol. 5, no. 1, pp. 1-13, 2016.

[11] C. O. Aksoy, K. Ogul, I. Topal, S. C. Ozer, V. Ozacar, and E. Posluk, "Numerical modeling of non-deformable support in swelling and squeezing rock," International Journal of Rock Mechanics and Mining Sciences, vol. 52, pp. 61-70, 2012.

[12] M. Bayerl, B. Danzebrink, K. Thyrock, K. Opolony, and I. Gollnick, "Application of Hilti one step bolts for roadway support in German deep coal mines," in Proceedings of 28th International Conference on Ground Control in Mining, pp. 59-69, Morgantown, WV, USA, July 2009.

[13] P. Choquet, "Design of steel arch supports for gate roadways," CIM Bulletin, vol. 79, no. 891, pp. 88-96, 1986.

[14] J. P. Loui, J. C. Jhanwar, and P. R. Sheorey, "Assessment of roadway support adequacy in some Indian manganese mines using theoretical in situ stress estimates," International Journal of Rock Mechanics and Mining Sciences, vol. 44, no. 1, pp. 148-155, 2007.

[15] A. Nierobisz, "Investigation of mine roadway support load during seismic events," Journal of Mining Science, vol. 48, no. 2, pp. 298-307, 2012.

[16] R. Ulusay, Ö. Aydan, M. Geniş, and T. Hisataka, "Stability assessment of avanos underground congress centre (Cappadocia, Turkey, in soft tuffs through an integrated scheme of rock engineering methods," Rock Mechanics and Rock Engineering, vol. 46, no. 6, pp. 1303-1321, 2013.

[17] R. Schwingenschloegl and C. Lehmann, "Swelling rock behaviour in a tunnel: NATM-support vs. Q-support-A 
comparison," Tunnelling and Underground Space Technology, vol. 24, no. 3, pp. 356-362, 2009.

[18] B. T. Shen, "Coal mine roadway stability in soft rock: a case study," Rock Mechanics and Rock Engineering, vol. 47, no. 6, pp. 2225-2238, 2013.

[19] M. C. He, W. L. Gong, J. Wang et al., "Development of a novel energy-absorbing bolt with extraordinarily large elongation and constant resistance," International Journal of Rock Mechanics and Mining Sciences, vol. 67, pp. 29-42, 2014.

[20] Y. Y. Jeong, H. M. Kang, S. H. Choi, and S. H. Cho, "Dynamic expansion rock bolt for rapid installing in rocks," Geosystem Engineering, vol. 18, no. 2, pp. 85-91, 2015.

[21] H. P. Kang, J. Lin, and Y. Z. Wu, "Development and applications of rock bolting materials for coal mine roadways," in Proceedings of 30th International Pittsburgh Coal Conference, pp. 136-154, Beijing, China, September 2013.

[22] S. C. Li, Q. Wang, W. T. Li et al., "Comparative field test study of pressure relief anchor box beam support system in deep thick top coal roadway," Chinese Journal of Rock Mechanics and Engineering, vol. 31, pp. 656-666, 2012.

[23] L. P. Srivastava and M. Singh, "Effect of fully grouted passive bolts on joint shear strength parameters in a blocky mass," Rock Mechanics and Rock Engineering, vol. 48, no. 3, pp. 1197-1206, 2015.

[24] L. G. Wang, J. Zhang, and H. L. Li, "A creep analysis of a boltgrouting support structure within a soft rock roadway," Journal of China University of Mining and Technology, vol. 38, pp. 607-612, 2009.

[25] N. G. Baxter, T. P. Watson, and B. N. Whittaker, "Study of the application of T-H support systems in coal mine gate roadways in the UK," Mining Science and Technology, vol. 10, no. 2, pp. 167-176, 1990.

[26] A. B. Szwilski, "Experience with mine roadway steel arch supports in the United Kingdom," CIM Bulletin, vol. 72, pp. 92-98, 1979.

[27] H. Yan, J. X. Zhang, L. Y. Li, and R. M. Feng, "Stability assessment of rock surrounding an I-beam supported retreating roadway," Journal of Central South University, vol. 22, no. 9, pp. 3598-3607, 2015.

[28] Y. Y. Jiao, L. Song, X. Z. Wang, and A. C. Adoko, "Improvement of the $\mathrm{U}$-shaped steel sets for supporting the roadways in loose thick coal seam," International Journal of Rock Mechanics and Mining Sciences, vol. 60, pp. 19-25, 2013.

[29] R. S. Yang, Q. H. Li, Q. Li, and X. L. Zhu, "Assessment of bearing capacity and stiffness in new steel sets used for roadway support in coal mines," Energies, vol. 10, no. 10, pp. 1-15, 2017.

[30] X. F. Sun, X. S. Fang, and L. T. Guan, Mechanics of Materials, Higher Education Press, Beijing, China, 2009.

[31] Y. Q. Long, S. H. Bao, and S. Yuan, Structural Mechanics I, Higher Education Press, Beijing, China, 2012. 


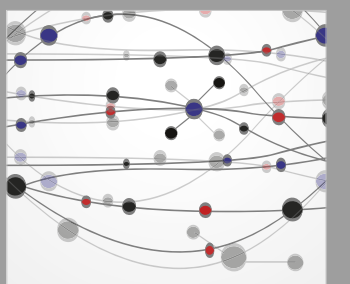

The Scientific World Journal
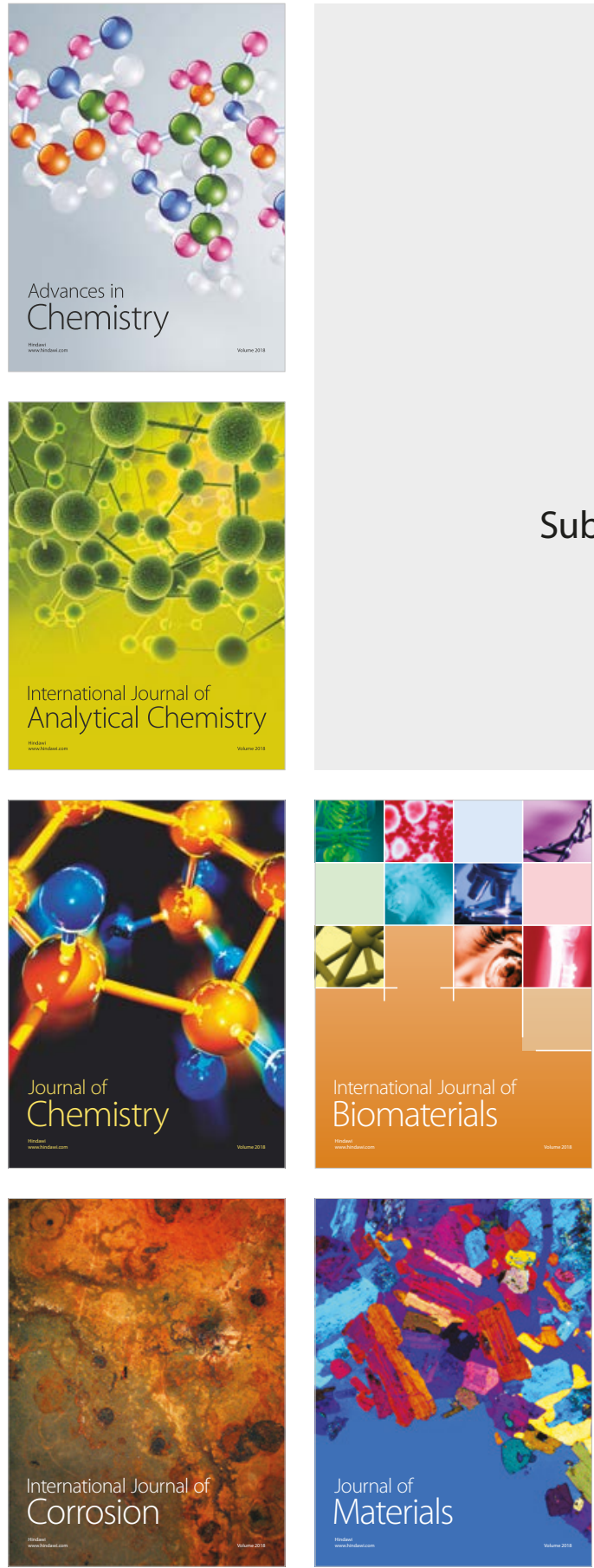

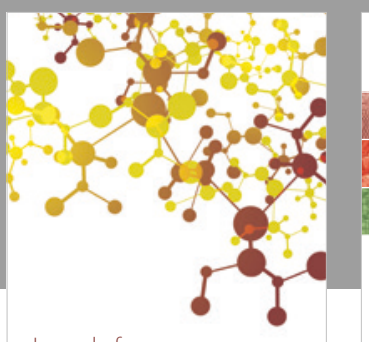

Journal of

Applied Chemistry
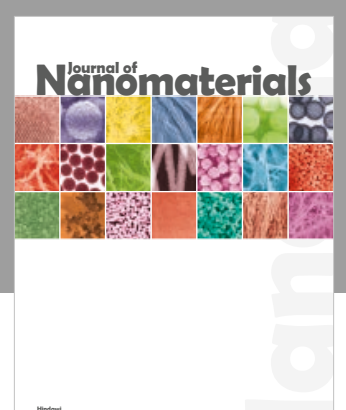

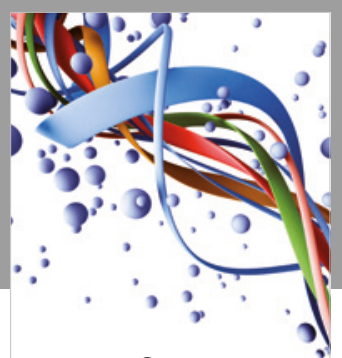

Scientifica

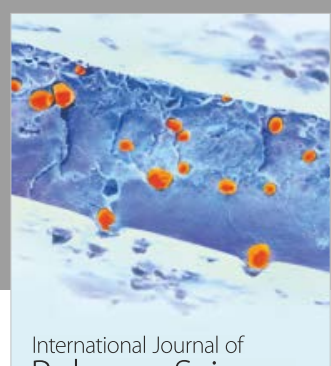

Polymer Science

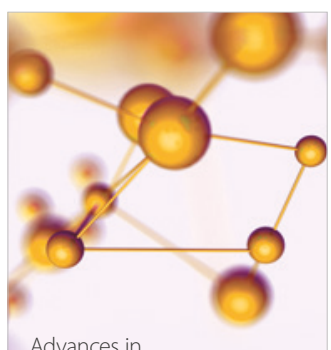

Physical Chemistry
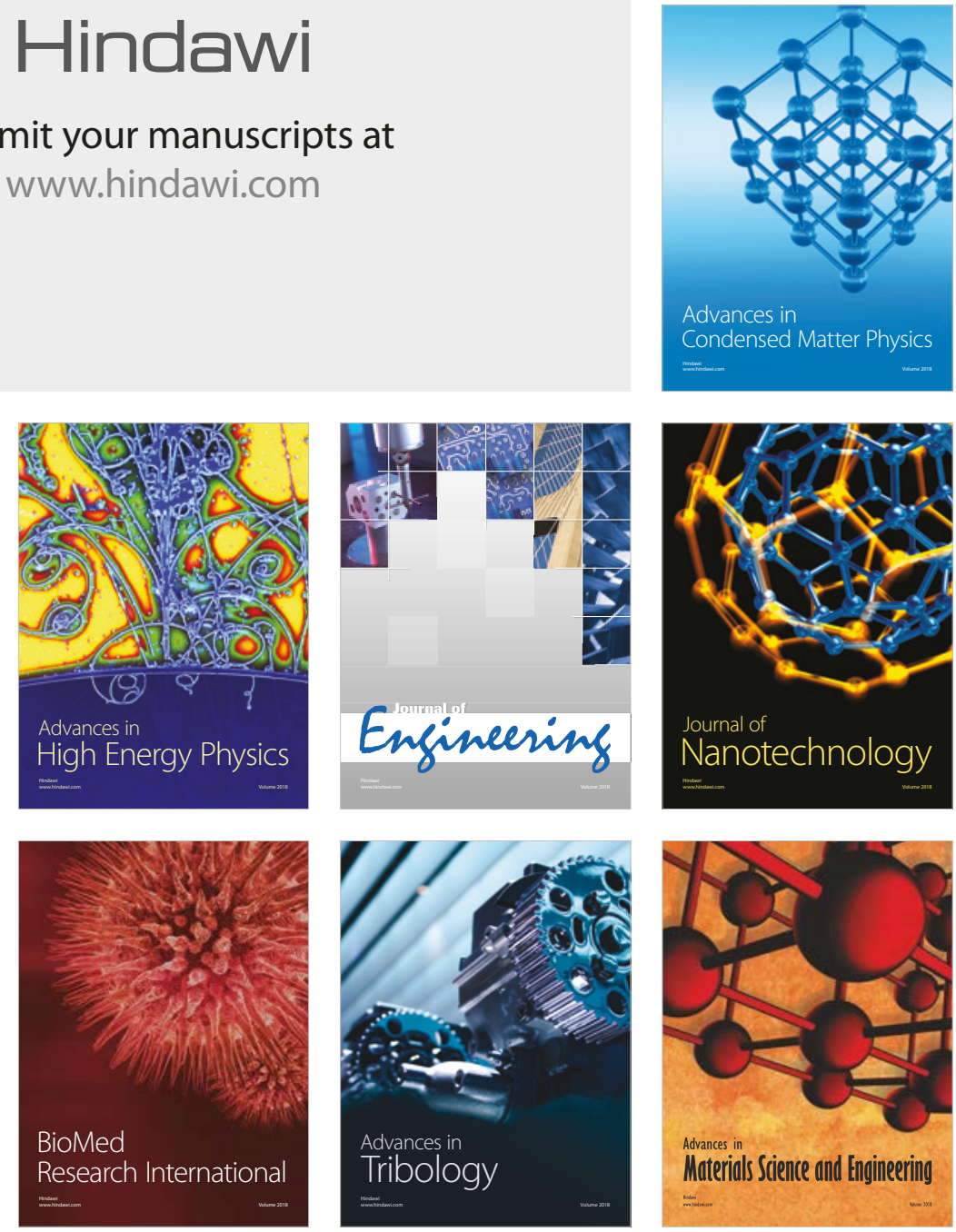